\title{
Chemistry of tetrathiomolybdate and tetraselenotungstate: Applications in carbohydrate chemistry*
}

\author{
Perali Ramu Sridhar, V. Saravanan, and S. Chandrasekaran ${ }^{\ddagger}$ \\ Department of Organic Chemistry, Indian Institute of Science, Bangalore-560012, \\ India
}

\begin{abstract}
An efficient one pot synthesis of thio and selenolevoglucosans from 1,6-diactivated carbohydrate derivatives has been achieved using benzyltriethylammonium tetrathiomolybdate, $\left[\mathrm{BnNEt}_{3}\right]_{2} \mathrm{MoS}_{4}$, as a sulfur transfer reagent and tetraethylammonium tetraselenotungstate, $\left[\mathrm{Et}_{4} \mathrm{~N}\right]_{2} \mathrm{WSe}_{4}$, as a selenium transfer reagent, respectively. The methodology has also been extended to the synthesis of 1,5-epithio and 1,5-episeleno pentoses.
\end{abstract}

\section{INTRODUCTION}

The reagents, benzyltriethylammonium tetrathiomolybdate, $\left[\mathrm{BnNEt}_{3}\right]_{2} \mathrm{MoS}_{4} \mathbf{1}$ [1], and tetraethylammonium tetraselenotungstate, $\left[\mathrm{Et}_{4} \mathrm{~N}_{2} \mathrm{WSe}_{4} 2\right.$ [2], have been shown to be useful for sulfur and selenium transfer reactions, respectively, in organic synthesis. Synthesis of disulfides from alkyl halides [3], ring opening of epoxides [4], tandem sulfur transfer/reduction/Michael addition [5] in one pot, and reduction of aryl azides to amines [6] and alkyl azides to imines [6] have been reported from our laboratory using the reagent tetrathiomolybdate $\mathbf{1}$. It has also been used for the selective deprotection of propargyloxycarbonyl (Poc) protective group for amines [7] in peptides and for alcohols [8] in carbohydrate chemistry. Recently, a regioselective reduction of anomeric azides [9] to amines using the reagent $\mathbf{1}$ has been reported. Reagent $\mathbf{1}$ has also been used, as a sulfur transfer reagent, for the synthesis of phosphorothioate oligonucleotides [10]. On the other hand, tetraselenotungstate $\mathbf{2}$ has been used for the formation of diselenides [2b] from alkyl halides and in the synthesis of selenium analogs of several amino acid derivatives [11] (Scheme 1).

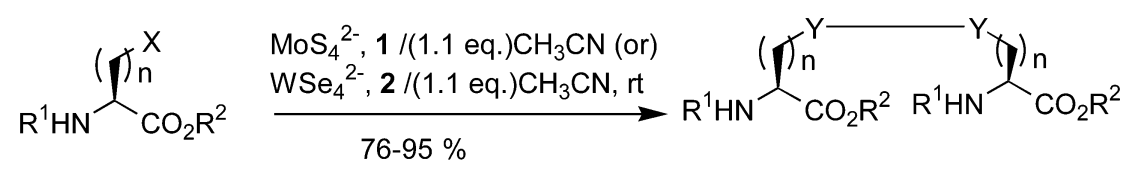

Scheme 1

In this article, we report on the utility of reagents $\mathbf{1}$ and $\mathbf{2}$ toward an efficient synthesis of thio and selenolevoglucosans, which are excellent synthons for the synthesis of deoxy sugar derivatives, involving a one pot sulfur/selenium transfer/reduction thiation/selenation reactions.

\footnotetext{
*Paper based on a presentation at the $24^{\text {th }}$ International Symposium on the Chemistry of Natural Products and the $4^{\text {th }}$ International Congress on Biodiversity, held jointly in Delhi, India, 26-31 January 2004. Other presentations are published in this issue, pp. 1-344.

${ }^{\ddagger}$ Corresponding author: Honorary Professor, Jawaharlal Nehru Centre for Advanced Scientific Research, Bangalore, India
} 


\section{SYNTHESIS OF SUGAR DISULFIDES AND SUGAR DISELENIDES}

Using the reagents 1 or $\mathbf{2}$ (1.1 equiv) we previously reported the synthesis of sugar disulfides [3c] and sugar diselenides, respectively [2b] (Scheme 2).

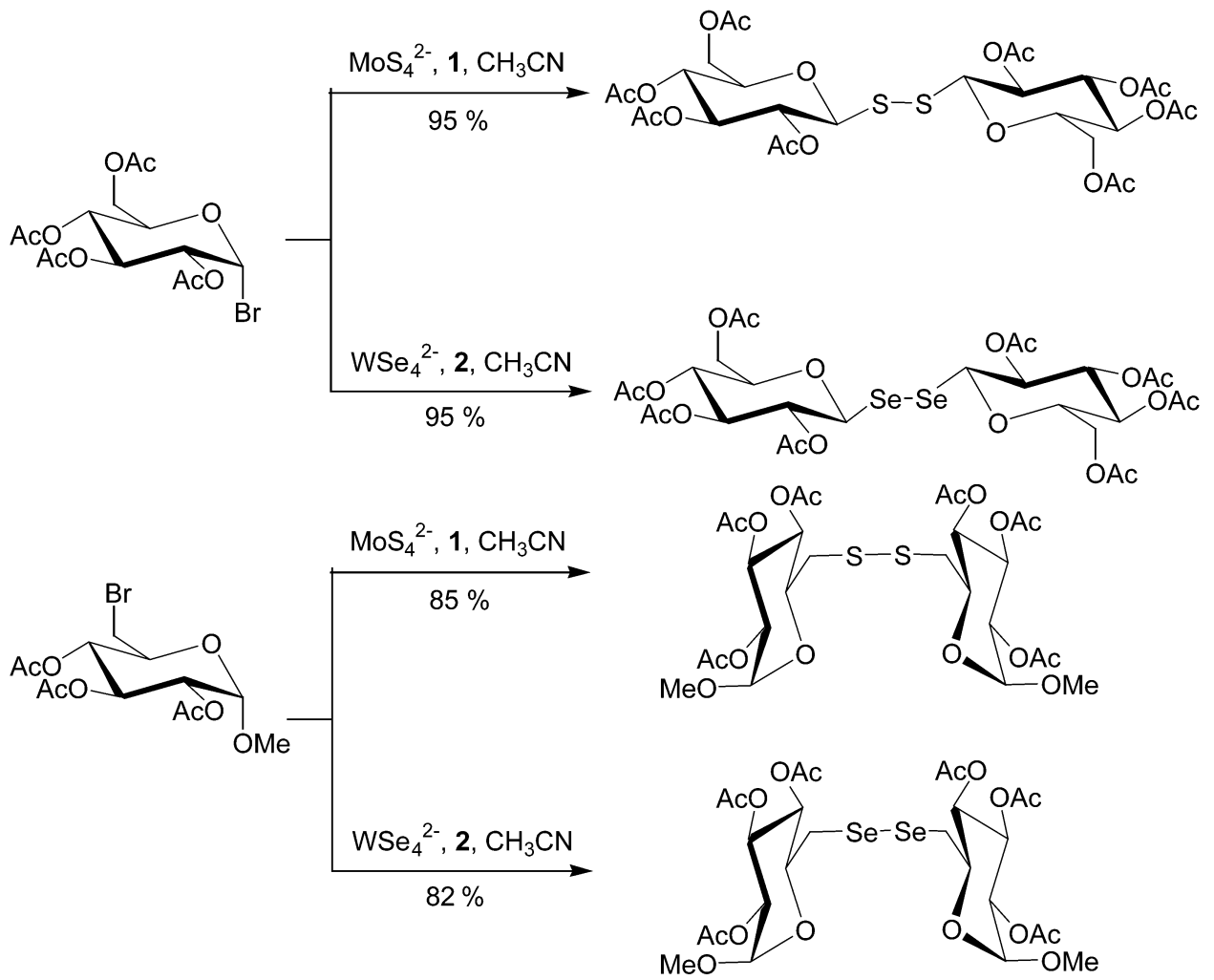

Scheme 2

\section{1,6-EPITHIO AND 1,6-EPISELENO- $\beta$-D-GLUCOPYRANOSES}

Thioglycosides have become increasingly important as glycosyl donors in the synthesis of oligosaccharides [12]. In particular, the 1,6-epithio derivative 8a and 1,6-episeleno- $\beta$-D-glucopyranose $\mathbf{8 b}$ are important building blocks in the synthesis of a variety of deoxy sugars since the two most reactive centers at C-1 and C- 6 are bridged and provide an opportunity for further synthetic manipulation. Akagi reported the first synthesis of thiolevoglucosan 8a in moderate yields [13], and subsequently similar approaches to 8a have been published [14]. More recently, a series of papers has been published on the efficient synthesis and use of 1,6-dideoxy-1,6-epithio and 1,6-dideoxy-1,6-episeleno sugars as glycosyl donors for the preparation of 6-deoxy sugars [15]. Our reagent tetrathiomolybdate 1 was used successfully for the first time by Stick for the synthesis of thiolevoglucosan 8a [15a], and we decided to expand and explore the versatility of reagent $\mathbf{1}$ in the synthesis of a variety of levoglucosan derivatives (Scheme 3). It was also of interest to study the use of tetraselenotungstate $\mathbf{2}$ for the synthesis of selenolevoglucosan derivatives (Fig. 1). 


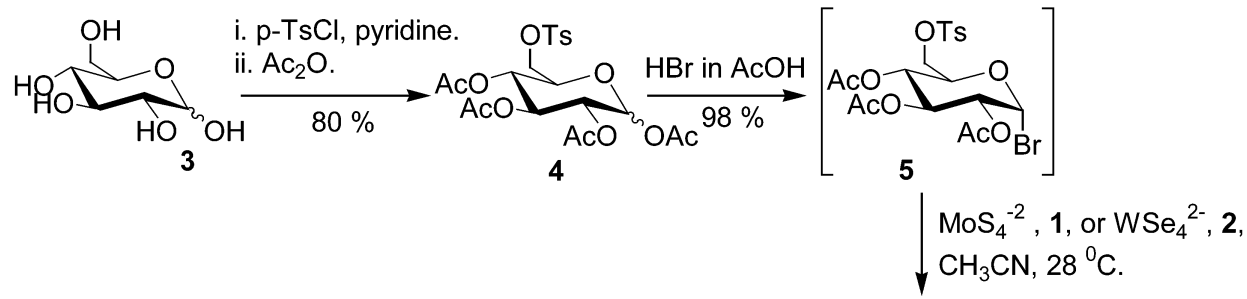

Scheme 3

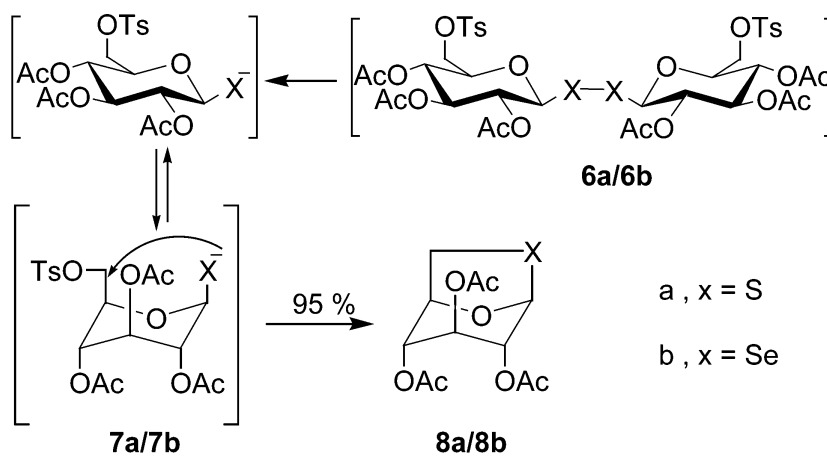

Fig. 1

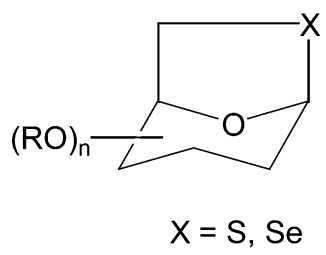

\section{Synthesis of 1,6-epithio and 1,6-episeleno sugar deravatives}

Treatment of 6- $O$-tosyl-1,2,3,4-tetra- $O$-acetyl- $\alpha$-D-glucopyranoside 4 with $\mathrm{HBr}$ in acetic acid gave the corresponding glycosyl bromide $\mathbf{5}$. The glycosyl bromide $\mathbf{5}$ was directly treated with tetrathiomolybdate 1 (1.2 equiv, $\mathrm{CH}_{3} \mathrm{CN}, 28{ }^{\circ} \mathrm{C}, 0.5 \mathrm{~h}$ ) to afford 2,3,4-tri- $O$-acetylthiolevoglucosan 8a in $95 \%$ yield. Similarly, the reaction of 5 with tetraselenotungstate $2\left(1.2\right.$ equiv, $\left.\mathrm{CH}_{3} \mathrm{CN}, 28^{\circ} \mathrm{C}, 0.5 \mathrm{~h}\right)$ led to the formation of 2,3,4-tri- $O$-acetylselenolevoglucosan $\mathbf{8 b}$ in $94 \%$ yield. The facile formation of 1,6-anhydrosugars $\mathbf{8 a}$ and $\mathbf{8 b}$ from $\mathbf{5}$ can be visualized to take place via sulfur transfer or selenium transfer at the anomeric carbon to form intermediate disulfide/diselenide $\mathbf{6 a} / \mathbf{6} \mathbf{b}$. The formation of sugar disulfide/diselenide from pyranosyl bromides with $\mathbf{1}$ or $\mathbf{2}$ has already been demonstrated in our laboratory [2b,3c]. The intermediate $\mathbf{6}$ possibly undergoes reductive cleavage to give the corresponding thiolate $7 \mathbf{a}$ or selenoate $\mathbf{7 b}$ involving an induced redox process [5] followed by displacement of the tosylate (Scheme 3).

Encouraged by these results, we applied this methodology to different carbohydrate derivatives. Treatment of 2-deoxy-1,3,4-tri- $O$-acetyl-6- $O$-tosyl- $\alpha$-D-glucopyranoside 9 [16] with $\mathrm{HBr}$ /acetic acid followed by the reaction with $\mathbf{1}$ gave 2-deoxy-3,4-di- $O$-acetythiolevoglucosan $\mathbf{1 0}$ [17] and on reaction with $\mathbf{2}$ afforded 2-deoxy-3,4-di- $O$-acetyselenolevoglucosan $\mathbf{1 1}$ in excellent yields. Compounds $\mathbf{1 0}$ and 11 can serve as excellent precursors toward the synthesis of natural products containing 2,6-dideoxy carbohydrate moieties. These can also be directly used as glycosyl donors as the anomeric position has been activated with sulfur/selenium.

The methodology was also extended to a galactose derivative. Treatment of 6-O-tosyl-1,2,3,4tetra- $O$-acetylgalactose 12 [15a] with $\mathrm{HBr} /$ acetic acid gave the corresponding galactose bromide, which 
upon treatment with 1 gave the corresponding 1,6-epithio derivative 13 [15a] (95\%) and on treatment with 2 yielded 1,6-episeleno- $\beta$-D-galactopyranose 14 (94\%) (Scheme 4).
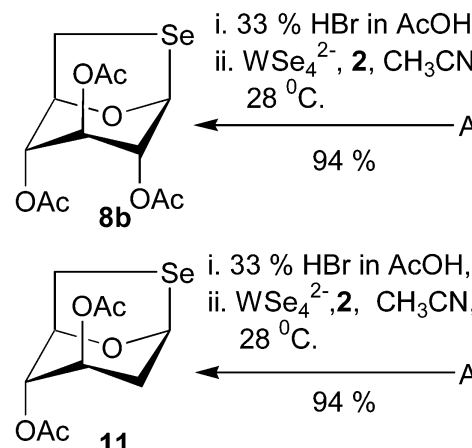

i. $33 \% \mathrm{HBr}$ in $\mathrm{AcOH}$, ii. $\mathrm{WSe}_{4}{ }^{2-}, 2, \mathrm{CH}_{3} \mathrm{CN}$,

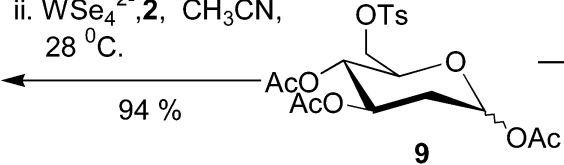

i. $33 \% \mathrm{HBr}$ in $\mathrm{AcOH}$,

ii. $\mathrm{MoS}_{4}{ }^{2-}, 1, \mathrm{CH}_{3} \mathrm{CN}$,

\section{,}

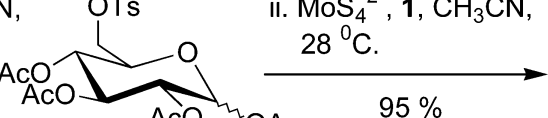

ACO ${ }^{4}$ OAC

$95 \%$

4

i. $33 \% \mathrm{HBr}$ in $\mathrm{AcOH}$,

ii. $\mathrm{MoS}_{4}{ }^{2-}, 1, \mathrm{CH}_{3} \mathrm{CN}$, $28{ }^{\circ} \mathrm{C}$.
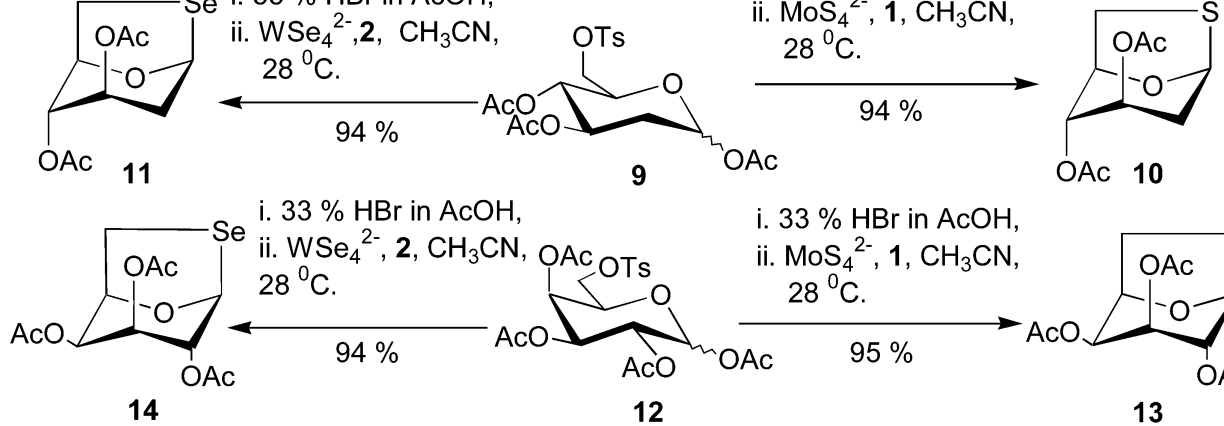

i. $33 \% \mathrm{HBr}$ in $\mathrm{AcOH}$,

ii. $\mathrm{MoS}_{4}{ }^{2-}, 1, \mathrm{CH}_{3} \mathrm{CN}$, $28^{\circ} \mathrm{C}$.

12

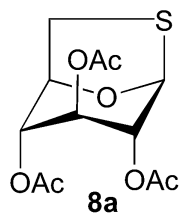

OAc 10

Scheme 4

\section{Synthesis of 2-deoxy-2-amino-1,6-epithio and 1,6-episeleno sugar derivatives}

Deoxy amino sugars are also of synthetic interest because of their increased therapeutic capabilities. In 1975, Yamamoto et al. [18] reported the synthesis of 2-acetamido-3,4-di- $O$-aetyl-2-deoxy-thiolevoglucosan 18 starting from 2-acetamido-3,4-di- $O$-acetyl-2-deoxy-6- $O$ - $p$-toluenesulfonyl- $\beta$-D-glucopyranosyl ethylxanthate. After this report, no other synthetic procedures were published for the synthesis of amino-thiolevoglucosans. Our attempt toward the synthesis of 2-acetamido-3,4-di$O$-aetyl-2-deoxy-thiolevoglucosan 18 started from the glucosamine hydrochloride $\mathbf{1 5}$. Neutralization of glucosamine hydrochloride 15 with $\mathrm{NaOMe} / \mathrm{MeOH}$ followed by treatment with $\mathrm{Ac}_{2} \mathrm{O}$ gave the corresponding $N$-acetylglucosamine $\mathbf{1 6}$ [19] in $90 \%$ yield. Tosylation of $\mathbf{1 6}$ followed by acetylation furnished 2 -acetamido-1,3,4-tri- $O$-acetyl-2-deoxy-6- $O$ - $p$-toluenesulfonyl- $\beta$-D-glucopyranose 17 [20] in moderate yield (50\%). Treatment of $\mathbf{1 7}$ with $\mathrm{HBr} / \mathrm{AcOH}$ followed by treatment with $\mathrm{MoS}_{4}{ }^{2-}$ (1) or $\mathrm{WSe}_{4}{ }^{2-}$ (2) furnished 2-acetamido-3,4-di- $O$-aetyl-2-deoxy-thiolevoglucosan $\mathbf{1 8}$ or 2-acetamido-3,4-di$O$-aetyl-2-deoxy-selenolevoglucosan 19, respectively, in excellent yield (95 and $75 \%$ ) (Scheme 5). On the other hand, treatment of glucosamine hydrochloride 15 with $p$-toluene sulfonylchloride in pyridine followed by acetylation gave the corresponding di-tosyl glucosamine derivative $\mathbf{2 0}$ in good yield $(60 \%)$. Compound 20 upon treatment with $\mathrm{HBr}$ in acetic acid followed by reaction with $\mathbf{1}$ afforded 2-deoxy-2-tosylamino-3,4-di- $O$-acetyl-1,6-epithioglucose 21 (87\%) and on treatment with 2 gave 2-deoxy-2-tosylamino-3,4-di- $O$-acetyl-1,6-episelenoglucose 22 (85\%) (Scheme 5). 


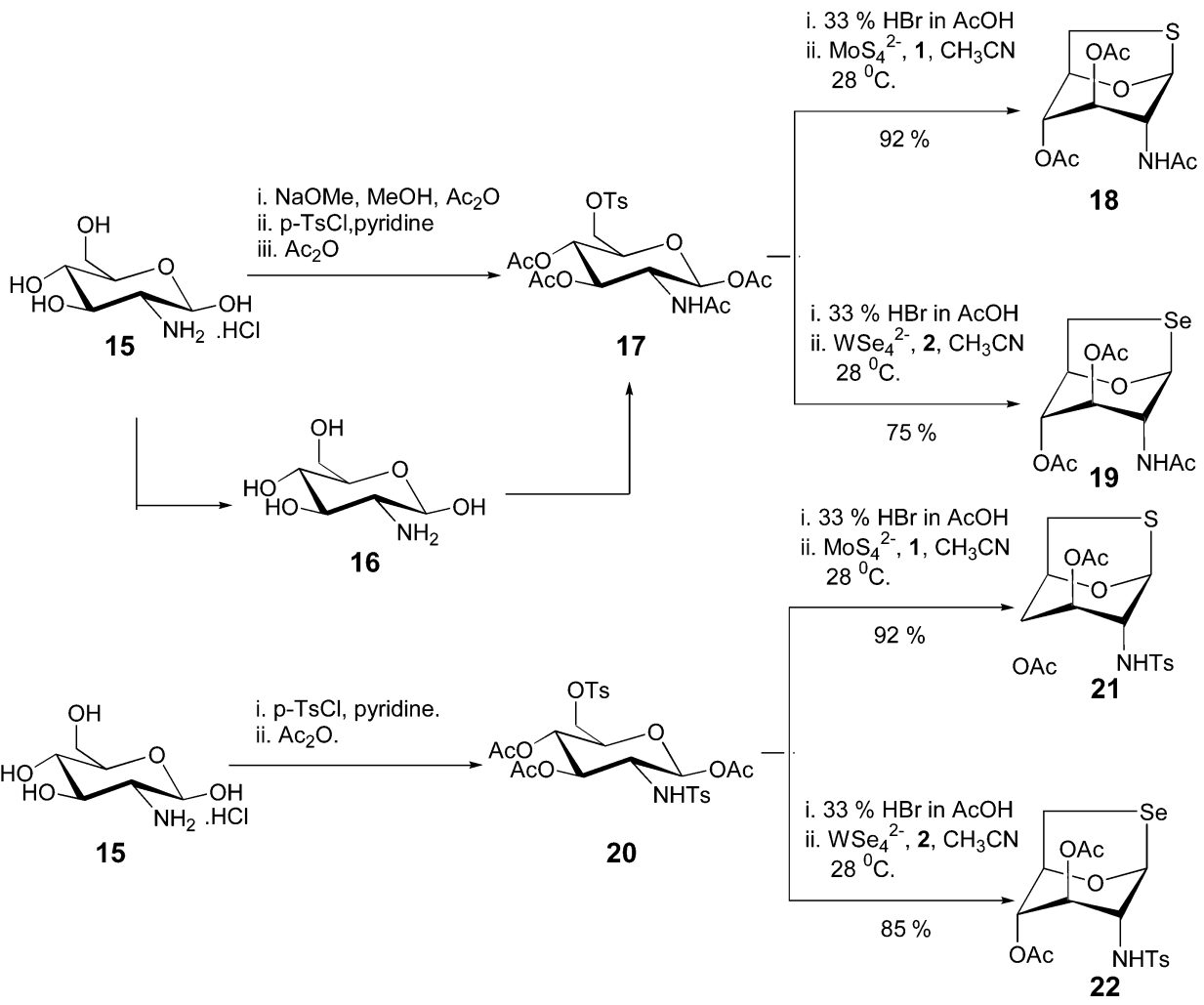

Scheme 5

\section{Synthesis of 2-deoxy-3-halo-1,6-epithio and 1,6-episeleno sugar derivatives}

2,3,6-Trideoxy systems are present as terminal sugars in natural products like aclacinomycin and act as intermediates in the synthesis of antibiotic amicetin [21]. In order to achieve the synthetic precursor for this class of molecules, we have chosen 3,4,6-tri- $O$-acetyl-D-glucal 23 [22] as a starting material. Deprotection of the acetates from 23 using $\mathrm{NaOMe} / \mathrm{MeOH}$ gave glucal 24 in $99 \%$ yield, which was selectively tosylated at C-6 hydroxyl and then acetylated the C-3 and C-4 hydroxyls using pyridine and acetic anhydride to furnish 6- $O$-tosyl-3,4-di- $O$-acetyl-D-glucal 25 [23] in $76 \%$ yield. Compound 25 was treated with $\mathrm{HBr}$ /acetic acid to get the dibromide 26 [16], which on treatment with tetrathiomolybdate 1 gave 2,3-dideoxy-3-bromo-4- $O$-acetyl-1,6-epithioglucopyranose 27 and on reaction with tetraselenotungstate 2 afforded 2,3-dideoxy-3-bromo-4- $O$-acetyl-1,6-episelenoglucopyranose 28, respectively, in very good yields ( $82 \%)$ (Scheme 6$)$. 

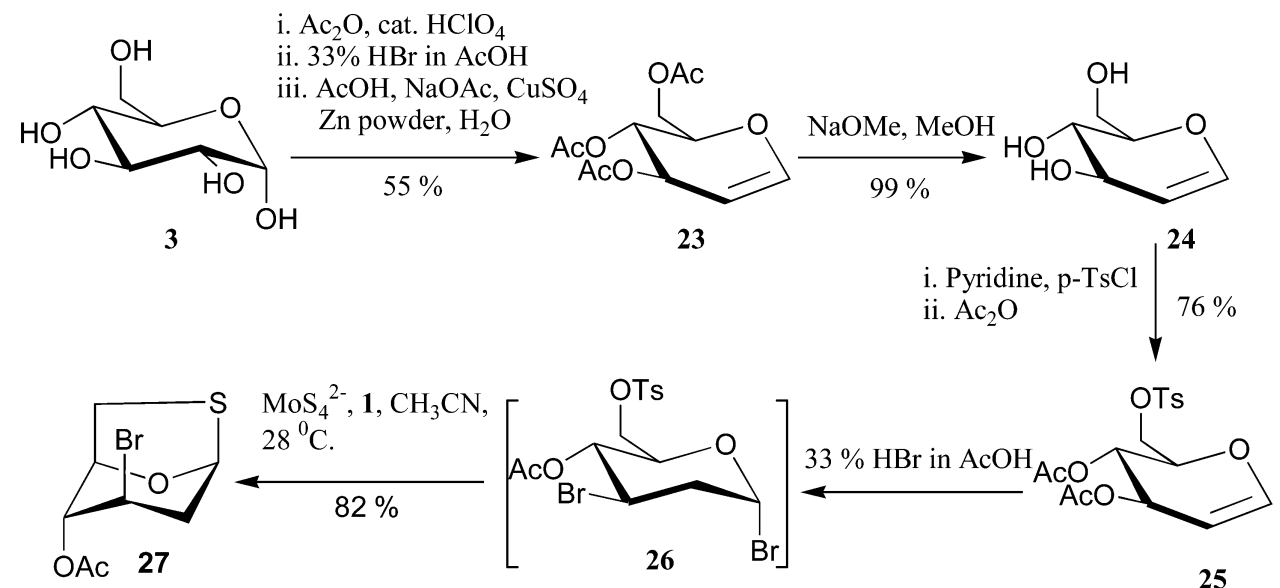
$82 \% \mid \begin{aligned} & \mathrm{WSe}_{4}{ }^{2-}, 2, \mathrm{CH}_{3} \mathrm{CN}, \\ & 28{ }^{0} \mathrm{C} .\end{aligned}$

Scheme 6

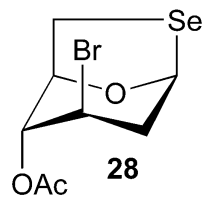

\section{Synthesis of 1,5-epithio and 1,5-episleno-D-ribose derivatives}

It was of interest to extend the scope of this reaction to the synthesis of 1,5-epithio/episeleno pentose derivatives. Accordingly, treatment of D-ribose 29 in acetone with cat. $\mathrm{H}_{2} \mathrm{SO}_{4}$ gave the selectively protected 2,3-isopropylidine-D-ribose $\mathbf{3 0}$ [24] in $85 \%$ yield.

Reaction of $\mathbf{3 0}$ with $p$-TsCl/pyridine furnished 5-O-tosyl-2,3-isopropylidine-D-ribose 31 [25] in $80 \%$ yield. Treatment of 5-O-tosyl-2,3-isopropylidine-D-ribose 31 with $\mathrm{SOCl}_{2}$ in dichloromethane gave the corresponding ribosyl chloride which was immediately treated with $\mathbf{1}$ to give the corresponding 1,5-epithio-2,3-isopropylidine-D-ribose 32 [26], and treatment of $\mathbf{3 1}$ with 2 afforded 1,5-episeleno2,3-isopropylidine-D-ribose $\mathbf{3 3}$ in very good yields (Scheme 7).

In studies directed toward the synthesis of 2,5-dideoxy ribose derivatives, 2-deoxyribose $\mathbf{3 4}$ was treated with cat. $\mathrm{HCl}$ in methanol to get the methyl-2-deoxy-ribofuranoside 35 [27] in $90 \%$ yield. Compound 35 was treated with $p$-TsCl in pyridine to furnish methyl 2-deoxy-3,5-di- $O$-tosyl-D-erythropentoside 36 [28]. Treatment of $\mathbf{3 6}$ with dry $\mathrm{HCl}$ in glacial acetic acid gave the corresponding 2-deoxy3,5-di-O-tosyl-D-erythro-pentosyl chloride derivative, which upon treatment with 1 gave 2-deoxy-1,5-epithio-3-O-tosyl-ribose 37 (65\%) and on reaction with 2 afforded 2-deoxy-1,5-episeleno-3-O-tosyl-ribose 38 (61\%) (Scheme 8).

It is important to mention that these 1,5-epithio or 1,5-episelenopentoses $(\mathbf{3 2}, \mathbf{3 3}, \mathbf{3 7}$, and $\mathbf{3 8})$ are excellent precursors for the synthesis of deoxynucleotides as well as for the synthesis of 2,3-dideoxy3-thiocytidine (3TC), [(+)-(2S,5R)-1-[2-(hydroxymethyl)-1,3-oxathiolan-5-yl]cytosine] (+)-BCH-189 which are potent anti-human immunodeficiency virus (HIV) active [29] and anti-human hepatitis B virus active [30]. 

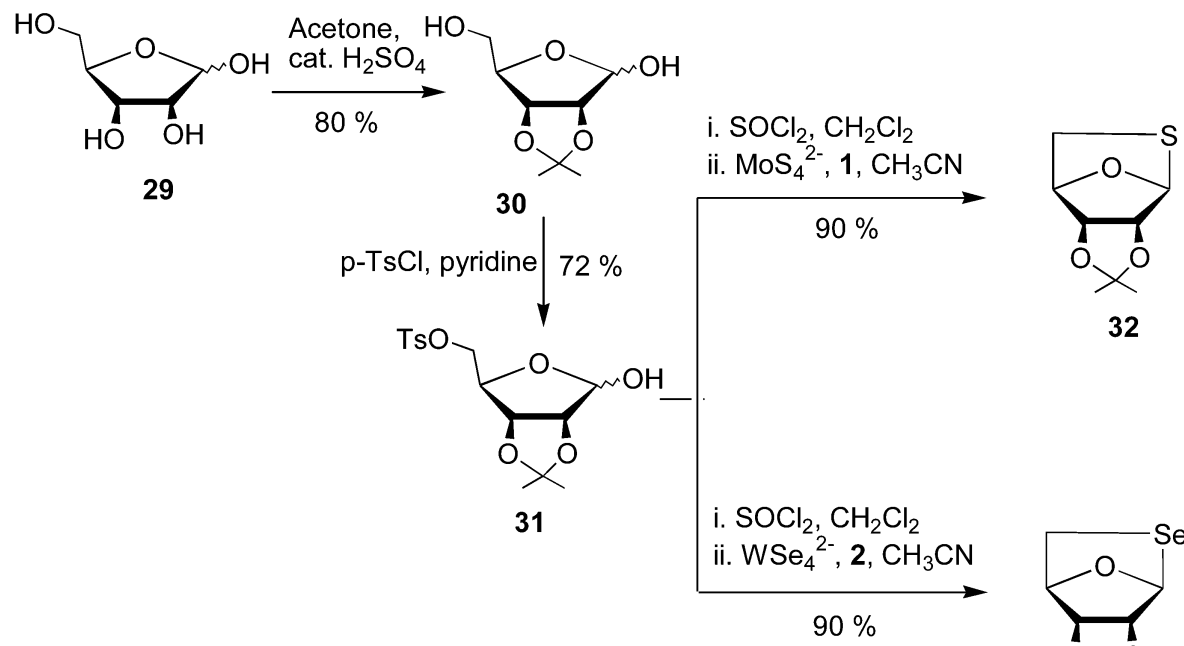

Scheme 7

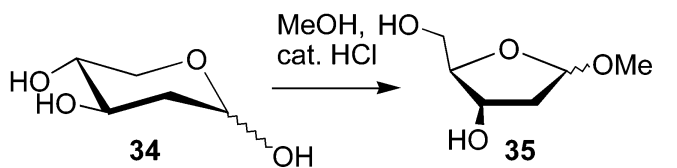

i. $\mathrm{HCl}$ (dry), $\mathrm{AcOH}$

ii. $\mathrm{MoS}_{4}{ }^{2-}, 1, \mathrm{CH}_{3} \mathrm{CN}$,

p-TsCl, pyridine $\begin{aligned} & 60 \% \text { (two } \\ & \text { steps) }\end{aligned}$ $28{ }^{\circ} \mathrm{C}$

$\mathrm{TsO}$

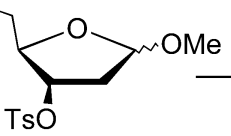

36

i. $\mathrm{HCl}$ (dry), $\mathrm{AcOH}$

ii. $\mathrm{WSe}_{4}{ }^{2-}, 2, \mathrm{CH}_{3} \mathrm{CN}$, $28{ }^{\circ} \mathrm{C}$.

$61 \%$

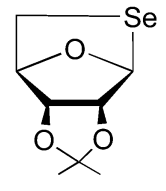

33

Scheme 8

\section{CONCLUSION}

In conclusion, we have developed an efficient methodology for the synthesis of epithio and episeleno hexoses and pentoses in good to excellent yields utilizing tetrathiomolybdate $\mathbf{1}$ and tetraselenotungstate $\mathbf{2}$ as key reagents for effecting the desired transformation. These derivatives are excellent precursors for the preparation of 6-deoxy, 1,6-dideoxy, 2,6-dideoxy, and 2,3,6-trideoxy hexoses as well as for 5-deoxy and 2,5-dideoxy pentose derivatives. 


\section{ACKNOWLEDGMENTS}

The authors thank the Volkswagen Foundation, Germany for financial support of this investigation. P.R.S. thanks the Council of Scientific and Industrial Research, New Delhi for a senior research fellowship.

\section{REFERENCES AND NOTES}

1. Review: K. R. Prabhu, N. Devan, S. Chandrasekaran. Synlett 1762-1778 (2002).

2. (a) S. O'Neil and J. W. Kolis. J. Am. Chem. Soc. 110, 1971-1973 (1988); (b) V. Saravanan, E. Porhiel, S. Chandrasekaran. Tetrahedron Lett. 44, 2257-2260 (2003).

3. (a) A. R. Remesha and S. Chandrasekaran. Synth. Commun. 22, 3277-3284 (1992); (b) A. R. Ramesha and S. Chandrasekaran. J. Org. Chem. 59, 1354-1357 (1994); (c) D. Bhar and S. Chandrasekaran. Carbohydr. Res. 301, 221-224 (1997).

4. N. Devan, P. Ramu Sridhar, K. R. Prabhu, S. Chandrasekaran. J. Org. Chem. 67, 9417-9420 (2002).

5. K. R. Prabhu, P. S. Sivanand, S. Chandrasekaran. Angew. Chem., Int. Ed. Eng. 31, 4316-4319 (2000).

6. A. R. Ramesha, S. Bhat, S. Chandrasekaran. J. Org. Chem. 60, 7682-7683 (1995).

7. (a) S. Sinha, S. Ilankumaran, S. Chandrasekaran. Tetrahedron Lett. 40, 771-774 (1999); (b) R. G. Bhat, S. Sinha, S. Chandrasekaran. Chem. Commun. 8, 812-813 (2002).

8. P. Ramu Sridhar and S. Chandrasekaran. Org. Lett. 4, 4731-4733 (2002).

9. P. Ramu Sridhar, K. R. Prabhu, S. Chandrasekaran. J. Org. Chem. 68, 5261-5264 (2003).

10. M. V. Rao and K. Macfarlane. Tetrahedron Lett. 35, 6741-6744 (1994).

11. R. G. Bhat, E. Porhiel, V. Saravanan, S. Chandrasekaran. Tetrahedron Lett. 44, 5251-5254 (2003).

12. P. J. Garegg. Adv. Carbohydr. Chem. Biochem. 52, 179-205 (1997).

13. M. Akagi, S. Tejima, M. Haga. Chem. Pharm. Bull. 11, 53-58 (1963).

14. (a) R. L. Whistler and P. A. Seib. Carbohydr. Res. 2, 93-103 (1966); (b) I. Lundt and B. SkelbækPedersen. Acta Chem. Scand., Ser. B 35, 637-642 (1981).

15. (a) H. Driquez, J. C. McAuliffe, R. V. Stick, D. M. G. Tilbrook, S. J. Williams. Aust. J. Chem. 49, 343-348 (1996); (b) R. V. Stick, D. M. G. Tilbrook, S. J. Williams. Aust. J. Chem. 52, 685-693 (1999); (c) B. W. Skelton, R. V. Stick, D. M. G. Tilbrook, A. H. White, S. J. Williams. Aust. J. Chem. 53, 389-397 (2000).

16. (a) V. Bailliez, R. M. de Figueiredo, A. Olesker, J. Cleophax. Synthesis 1015-1017 (2003); (b) M. V. Rosenthal and R. A. Zingaro. Carbohydr. Res. 84, 341-349 (1980).

17. T. Maki and S. Tejima. Chem. Pharm. Bull. 15, 1367-1372 (1967).

18. K. Yamamoto, M. Haga, S. Tejima. Chem. Pharm. Bull. 23, 233-236 (1975).

19. D. Haarton. Org. Synth. 46, 1-5 (1966).

20. J. Kadokawa, M. Sato, M. Karasu, H. Tagaya, K. Chiba. Angew. Chem., Int. Ed. 37, 2373-2376 (1998).

21. E. L. Albano and D. Horton. J. Org. Chem. 34, 3519-3522 (1969).

22. Z. J. Witczak, H. Chen, P. Kafplon. Tetrahedron: Asymmetry 11, 519-532 (2000).

23. P. Jargilis and F. W. Lichtenthaler. Tetrahedron Lett. 23, 3781-3784 (1982).

24. M. P. Sibi, J. Lu, J. Edwards. J. Org. Chem. 62, 5864-5872 (1997).

25. D. H. R. Barton, J. Camara, X. Cheng, S. D. Gero, J. Cs. Jaszberenyi, B. Quiclet-Sire. Tetrahedron 48, 9261-9276 (1992).

26. A. Fleetwood and N. A. Hughes. Carbohydr. Res. 317, 204-209 (1999).

27. M. S. Motawia and E. B. Pedersen. Liebigs Ann. Chem. 599-602 (1990).

28. E. Bozo, S. Boros, J. Kuszmann. Carbohydr. Res. 321, 52-66 (1999). 
29. (a) R. F. Schinazi, C. K. Chu, A. Peck, A. McMillan, R. Mathis, D. Cannon, L.-S. Jeong, J. W. Beach, W.-B. Choi, S. Yeola, D. C. Liotta. Antimicrob. Agents Chemother. 36, 672-676 (1992); (b) K. C. Chung, J. W. Beach, L. S. Jeong, B. G. Choi, F. I. Comer, A. J. Alves, R. F. Schinazi. J. Org. Chem. 56, 6503-6505 (1991).

30. (a) S.-L. Doong, C.-H. Tsai, R. F. Schinazi, D. C. Liotta, Y.-C. Chen. Proc. Natl. Acad. Sci. USA 88, 8495-8499 (1991); (b) J. W. Beach, L. S. Jeong, A. J. Alves, D. Pohl, H. O. Kim, C.-N. Chang, S.-L. Doong, R. F. Schinazi, Y.-C. Cheng, C. K. Chu. J. Org. Chem. 57, 2217-2219 (1992). 